\section{KAJIAN HARGA SEWA BANGUNAN KOMERSIAL DI KORIDOR JALAN RAYA KALIMALANG, JAKARTA}

\author{
Ajeng Laras Adhiani* dan Ragil Haryanto \\ Departemen Perencanaan Wilayah dan Kota, Fakultas Teknik, Universitas Diponegoro, Semarang
}

Jurnal Pengembangan Kota (2016) Volume 4 No. 2 (186-196) Tersedia online di: http://ejournal2.undip.ac.id/index.php/jpk DOI: 10.14710/jpk.4.2.186-196

\begin{abstract}
Abstrak. Koridor Jalan Raya Kalimalang merupakan kawasan yang berkembang pesat dan memiliki harga lahan yang tinggi karena adanya aktivitas komersial. Hal ini menjadikan pemilik lahan lebih memilih untuk menyewakan bangunan yang berada di atas lahan miliknya karena dianggap lebih menguntungkan. Penelitian ini bertujuan untuk menganalisis harga sewa bangunan di koridor Jalan Raya Kalimalang, Jakarta beserta faktor-faktor yang mempengaruhinya terkait aktivitas komersial. Metode penelitian yang digunakan yaitu metode kuantitatif. Temuan studi yang diperoleh adalah perkembangan aktivitas komersial di koridor Jalan Raya Kalimalang dipengaruhi oleh faktor lokasi, aksesibilitas, infrastruktur, dan kesesuaian kawasan. Harga sewa bangunan di koridor Jalan Raya Kalimalang mulai dari Rp20.000.000 - Rp100.000.000/ tahun. Aktivitas komersial di koridor Jalan Raya Kalimalang semakin berkembang. Hal ini dapat dilihat dari semakin meningkatnya permintaan, tetapi tidak diimbangi dengan ketersediaan bangunan yakni hanya 9,04\%. Terdapat sembilan faktor yang mempengaruhi harga sewa bangunan di koridor Jalan Raya Kalimalang, yaitu faktor ketersediaan bangunan, tata letak bangunan, lokasi, asal konsumen, kesesuaian koridor, luas bangunan, usia bangunan, kondisi bangunan, dan faktor jangka waktu sewa.
\end{abstract}

Kata Kunci: Harga Sewa Bangunan; Aktivitas Komersial; Koridor Jalan Raya Kalimalang

[Title: The Study Of Commercial Building Rental Prices in Kalimalang Street Corridor, Jakarta]. Kalimalang Street Corridor is a rapid growing area in Jakarta and has a high land price for commercial activities. It makes land owners prefer to rent their building to gain more profitable. This study aimed to analyze the rental price of the building in Kalimalang Street Corridor, Jakarta and its influencing factors related to commercial activities. The research method used was quantitative method. This research found that the development of commercial activities in Kalimalang street Corridor is influenced by location, accessibility, infrastructure and regional suitability. The rental price of the building in Kalimalang Street Corridor is Rp 20,000,000-100,000,000/year. Commercial activity in this street is always growing. It can be seen from the increasing demand of building, but it is not in line with the availability of the building which is only $9.04 \%$. There are nine factors that affect the rental price of the building in this are, that is, availability of building, layout of the building, location, origin of the consumer, suitability of the corridor, building area, age of the building, condition of buildings, and the lease term.

Keyword: Rental Building; Commercial activity; Kalimalang street Corridor

Cara mengutip: Adhiani, A L., Haryanto, R (2016). Kajian Harga Sewa Bangunan Komersial di Koridor Jalan Raya Kalimalang, Jakarta. Jurnal Pengembangan Kota. Vol 4 (2): 186-196. DOI: 10.14710/jpk.4.2.186-196

\section{PENDAHULUAN}

Penduduk Kota Jakarta mengalami peningkatan yang cukup pesat dari tahun ke tahun (Winarso, Hudalah, \& Firman, 2015). Jakarta Timur merupakan kota di DKI Jakarta dengan penduduk terbanyak. Hal ini disebabkan letaknya yang berdekatan dengan Kota Bekasi dan harga lahan yang relatif lebih murah dibandingkan wilayah pusat Jakarta.

Kawasan Kalimalang merupakan salah satu kawasan di Jakarta Timur dengan fungsi sebagai kawasan perkantoran, perdagangan, jasa, dan campuran yang sudah diatur dalam rencana detail tata ruang kota untuk memenuhi kebutuhan penduduk di pinggir Jakarta. Aktivitas komersial di Kawasan Kalimalang terutama pada koridor Jalan Raya Kalimalang berkembang dengan pesat. Harga lahan dan bangunan di kawasan tersebut terus mengalami peningkatan. Hal ini dikarenakan Kawasan Kalimalang merupakan penopang perekonomian bagi wilayah pinggir Jakarta. Letaknya yang berbatasan langsung dengan Kota Bekasi menjadikan penawaran dan permintaan akan lahan dan bangunan selalu meningkat. Harga lahan dipengaruhi oleh dua faktor, yaitu penawaran dan permintaan (Wijaya, 1999). Penawaran merupakan kemampuan kondisi lahan, seperti ketersediaan aksesibilitas, tingkat

ISSN: 2337-7062 (Print), 2503-0361 (Online) (C) 2016

This is an open access article under the CC-BY-NC-ND license (http://creativecommons.org/licenses/by-nc-sa/4.0/). - lihat halaman depan (c) 2016

*Email: ajeng.laras16@pwk.undip.ac.id HP. 08561785831

Diterima 2 September 2016, disetujui 1 November 2016 
pelayanan, kesesuaian fisik lahan, fasilitas, infrastruktur, serta kebijakan pembangunan rencana tata guna lahan (Capello \& Faggian, 2002; Dal Colle, 2016). Sedangkan, permintaan lahan meliputi finansial dan kebutuhan lahan.

Tingginya permintaan akan lahan dan bangunan oleh pelaku usaha untuk aktivitas komersial serta tidak adanya lahan dan bangunan yang kosong menjadikan harga bangunan komersial di koridor Jalan Raya Kalimalang semakin meningkat tiap tahunnya. Hal ini memicu terjadinya lahan sewa, dimana pemilik lahan menyewakan lahan beserta bangunan miliknya kepada pelaku usaha dalam jangka waktu tertentu. Fenomena ini terjadi karena pemilik lahan belum atau tidak ingin menjual lahan dan bangunan miliknya, namun tetap ingin mendapatkan nilai tambah atas aset yang dimiliki. Lahan sewa dianggap lebih menguntungkan bagi pemilik lahan maupun penyewa dibanding dengan jual-beli lahan karena pemilik lahan masih mendapatkan nilai tambah atas lahannya serta penyewa lahan tidak dibebani membayar lahan dengan harga yang tinggi pada satu waktu.

Aktivitas komersial adalah kegiatan pertukaran atau jual/ beli barang dan jasa untuk mendapatkan keuntungan dengan cara perdagangan dan seluruh kegiatan pendukungnya, seperti transportasi, komunikasi, perbankan, dan sebagainya (Sungguh, 1992). Kegiatan komersial berupa toko menurut Balchin, Kieve, dan Bull (1988) dibagi menjadi lima kategori, yaitu convenience shop dimana konsumen yang membeli barang pada toko jenis ini biasanya secara reguler, shopping shop dimana barang-barang yang dibeli pada toko jenis ini biasanya kurang reguler, specialty shop dimana pada toko jenis ini interval konsumen dalam membeli barang cukup lama dan tidak jelas, department and multiple store dimana dalam satu bangunan berisi banyak jenis toko, serta service shop yang biasanya berupa workshop dan tempat grosir (Wang, dkk., 2016).

Pola perkembangan aktivitas komersial menurut Hartshorn (1992) dibagi menjadi tiga klasifikasi, yaitu pusat (centers) yaitu memusatnya berbagai kegiatan komersial pada satu lokasi yang membentuk hierarki; mengikuti jaringan jalan (ribbon) yaitu tersebarnya beragam aktivitas komersial di sepanjang sisi koridor jalan yang yang terencana maupun yang tidak terencana; serta kawasan khusus (sprecialized areas) yaitu pengelompokan aktivitas komersial dengan komoditas tertentu yang sama/ saling terkait. Perkembangan aktivitas komersial dipengaruhi oleh empat faktor (Kaiser, 2009), yaitu aksesibilitas terhadap pasar dan akses langsung untuk lalu lintas, ketersediaan utilitas, jangkauan lokasi, serta kesesuaian kawasan.

Menurut Clark dan Pennington-Cross (2016) sewa lahan merupakan bagian dari model struktural yang lebih besar dimana suatu perusahaan atau perseorangan harus memutuskan apakah akan memiliki properti atau menyewa properti yang akan digunakannya dengan melihat pertimbangan lokasi dan struktur sewa yang baik. Tidak adanya nilai pasar yang jelas untuk karakteristik tertentu, seperti bentuk dan ukuran bangunan dalam penentuan harga sewa lahan memunculkan harga yang berbeda-beda pada setiap properti. Pada konteks ruang sewa, harga sewa mewakili nilai tempat penyewa pada atribut fisik ruang dan bangunan, atribut lokasi, atribut sewa, serta penyediaan atribut-atribut tersebut di pasar. Berdasarkan UU No. 12 Tahun 1994 Harga sewa bangunan yang umum digunakan meliputi harga pasar dan NJOP. Harga sewa bangunan berdasarkan NJOP dapat digunakan untuk melakukan perhitungan penetapan harga sewa bangunan berdasarkan nilai ekonomi dari setiap bangunan komersial (Kurniati \& Erlambang, 2015).

Menurut Tarigan (2005) lokasi yang berada pada zona pusat kota merupakan lokasi yang cocok dikembangkan menjadi kawasan komersial atau produktif. Hal ini dikarenakan adanya pengaruh aksesibilitas yang tinggi dan lokasi yang strategis. Lahan yang berada di lokasi strategis akan mempunyai nilai tinggi dan akan dijual/ disewa kepada penawar tertinggi ( $\mathrm{Hu}, \mathrm{Yang}$, Li, Zhang, \& Xu, 2016; Wang, dkk., 2016). Hal tersebut dilakukan untuk memperoleh keuntungan yang besar. Lokasi yang mempunyai penawaran tertinggi adalah lokasi yang berkaitan dengan penggunaan lahan, seperti perumahan, industri, serta komersial (Du, Thill, \& Peiser, 2016; Yunus, 2005). 
Menurut Clark dan Pennington-Cross (2016) roperti, sewa, dan tingkat demografi memiliki peran yang penting dalam menentukan harga sewa lahan di suatu perkotaan. Terdapat enam parameter yang mempengaruhi pasar sewa pada suatu properti (Čeh, Viitanen, \& Peruš, 2012), yaitu akses menuju jalan raya, tingkat kepadatan lalu lintas, akses menuju transportasi publik, jarak dengan pusat perbelanjaan, tingkat kepadatan bangunan kantor, dan usia efektif properti tersebut. Menurut Chong, Shui, dan Wong (2014), Lokasi menjadi salah satu faktor definitif dalam menentukan harga suatu properti, baik harga sewa maupun harga jual-beli, dimana harga properti di setiap lokasi berbeda-beda, salah satunya dengan melihat jarak antara lokasi properti dengan Central Business District (CBD).

Penetapan harga sewa bangunan komersial harus mempertimbangkan faktor-faktor pembentuk harga sewa bangunan komersial agar harga sewa bangunan komersial menjadi ideal. Namun, pada kenyataannya belum ada faktor yang pasti dalam penetapan dan perkembangan harga sewa bangunan khususnya di kawasan komersial. Oleh karena itu perlu diketahui "Faktor apa saja yang mempengaruhi harga sewa bangunan komersial di koridor Jalan Raya Kalimalang?".

\section{METODE PENELITIAN}

Penelitian mengenai kajian harga sewa bangunan komersial di koridor Jalan Raya Kalimalang, Jakarta menggunakan pendekatan kuantitatif. Teknik pengumpulan data dilakukan melalui data primer dan sekunder. Data primer berupa kuesioner dan observasi lapangan. Sedangkan, data sekunder melalui kajian literatur dan telaah dokumen. Pendekatan kuantitatif yang digunakan bersifat deskriptif. Teknik analisis yang digunakan adalah teknik analisis deskriptif kuantitatif dan analisis crosstab. Analisis deskriptif kuantitatif digunakan pada analisis kelompok aktivitas komersial, analisis harga sewa bangunan komersial, dan analisis pengaruh perkembangan aktivitas komersial terhadap harga sewa bangunan koridor Jalan Raya Kalimalang. Sedangkan, analisis crosstab digunakan pada analisis faktor-faktor yang mempengaruhi harga sewa bangunan komersial koridor Jalan Raya Kalimalang.

Teknik sampling yang digunakan pada penelitian ini adalah simple random sampling (Sugiyono, 2013) dengan jumlah sampel sebanyak 66 responden. Data yang dikumpulkan melalui kuesioner antara lain berupa ketersediaan bangunan komersial, tata letak bangunan, aksesibilitas, utilitas, masalah lingkungan, lokasi, asal konsumen (Kheir \& Portnov, 2016), kesesuaian koridor sebagai kawasan komersial, bentuk bangunan, luas bangunan, usia bangunan, kondisi bangunan, jangka waktu sewa, serta harga sewa bangunan.

\section{HASIL DAN PEMBAHASAN}

Karakteristik Aktivitas Komersial Koridor Jalan Raya Kalimalang. Berdasarkan hasil observasi lapangan dapat dilihat bahwa koridor Jalan Raya Kalimalang didominasi oleh properti komersial untuk aktivitas perdagangan dan jasa yang dikelompokkan menjadi 33 jenis usaha dengan rincian 19 jenis usaha perdagangan dan 14 jenis usaha jasa. Berdasarkan kondisi eksisting, aktivitas komersial di Koridor Jalan Raya Kalimalang berkembang mengikuti jaringan jalan (ribbon). Namun, pertumbuhan aktivitas komersial tersebut hanya terkonsentrasi di sisi bagian utara koridor Jalan Raya Kalimalang. Hal ini dikarenakan adanya sungai Kalimalang dan belum adanya jaringan jalan yang memadai pada sisi bagian selatan koridor Jalan Raya Kalimalang.

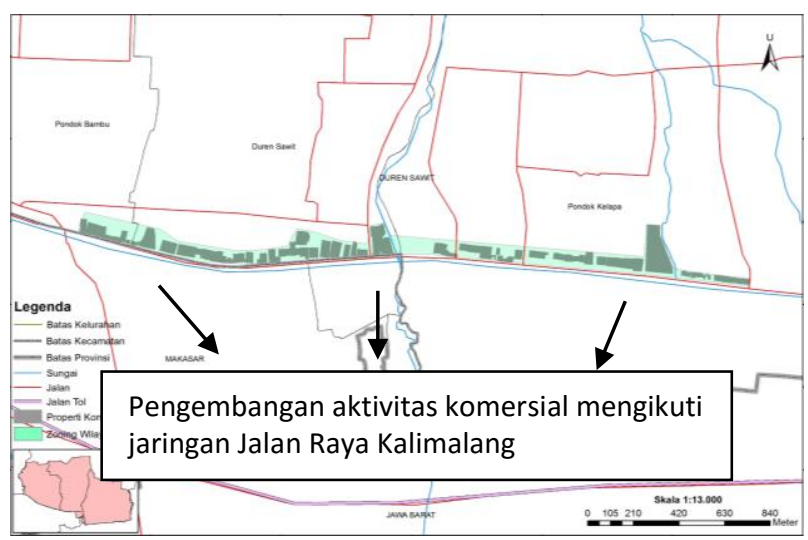

Gambar 1. Peta Persebaran Aktivitas Komersial Koridor Jalan Raya Kalimalang 
Gambar 1 menunjukkan persebaran aktivitas komersial di koridor Jalan Raya Kalimalang. Apabila dilihat dari bentuk kegiatannya, tidak ada pengkhususan bentuk aktivitas tertentu. Skala usaha yang ada di sepanjang koridor Jalan Raya Kalimalang cukup beragam, mulai dari lokal (primer), kawasan (sekunder), hingga kota (tersier). Beragamnya skala usaha yang ada di sepanjang koridor Jalan Raya Kalimalang menandakan bahwa konsumen yang datang tidak hanya berasal dari sekitar Kalimalang saja, tetapi juga dari wilayah lain (luar Jakarta Timur dan Bekasi). Pada skala usaha tingkat lokal mayoritas konsumen berasal dari sekitar Kalimalang. Pada skala usaha tingkat kawasan mayoritas konsumen berasal dari sekitar Kalimalang hingga sekitar Kecamatan Duren Sawit, sedangkan pada skala usaha tingkat kota konsumen tidak hanya berasal dari sekitar Kalimalang dan Kecamatan Duren Sawit, tetapi hingga luar Jakarta Timur dan Kota Bekasi. Dengan demikian, dapat dikatakan bahwa adanya aktivitas komersial di koridor Jalan Raya Kalimalang tidak hanya memenuhi kebutuhan konsumen di sekitar Kalimalang, tetapi juga untuk memenuhi kebutuhan konsumen dalam cakupan yang lebih luas (luar Jakarta Timur dan Kota Bekasi).

Perkembangan aktivitas komersial di koridor Jalan Raya Kalimalang dapat dilihat dari perbedaanperbedaan fisik dan nonfisik yang dipengaruhi oleh faktor-faktor berikut:

(a) Lokasi. Kesesuaian lokasi aktivitas komersial di koridor Jalan Raya Kalimalang dapat dikaitkan dengan lokasi lain di sekitarnya, yaitu lokasi terhadap kawasan permukiman, pendidikan, dan akses sarana umum. Koridor Jalan Raya Kalimalang dikatakan strategis karena lokasinya yang sangat dekat dengan kawasan permukiman. Hal ini sangat menguntungkan dikarenakan kawasan permukiman merupakan salah satu sumber permintaan (demand) aktivitas komersial yang letaknya perlu dipertimbangkan untuk pengoptimalan jangkauan konsumen. Jarak antara koridor Jalan Raya Kalimalang dengan kawasan permukiman relatif dekat yaitu 0,2-3 km (lihat gambar 2).

Selain kawasan permukiman, koridor Jalan Raya Kalimalang juga berdekatan dengan kawasan pendidikan. Kawasan pendidikan menjadi salah satu sumber permintaan aktivitas komersial di koridor Jalan Raya Kalimalang terutama bagi skala usaha lokal (bimbingan belajar dan fotocopy). Jarak antara koridor Jalan Raya Kalimalang dengan kawasan pendidikan relatif dekat yaitu 0,16-1,9 $\mathrm{km}$.

Akses sarana umum yang terdapat di koridor Jalan Raya Kalimalang untuk menunjang aktivitas komersial antara lain ialah musholla, masjid, gereja, rumah sakit, klinik, apotek, Polsek Duren Sawit, serta SPBU. Hingga saat ini, koridor Jalan Raya Kalimalang telah memiliki kemudahan akses terhadap sarana umum tersebut. Kedekatan terhadap kawasan permukiman, pendidikan, serta kemudahan dalam mengakses sarana umum menjadi faktor pendorong yang mempengaruhi perkembangan aktivitas komersial di koridor Jalan Raya Kalimalang.

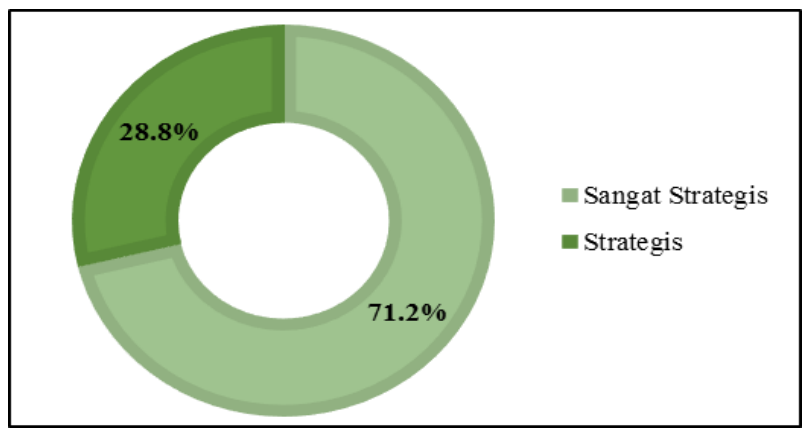

Gambar 2. Persentase Responden dalam Variabel Lokasi Koridor Jalan Raya Kalimalang

(b) Aksesibilitas. Tinggi atau rendahnya tingkat aksesibilitas pada suatu lokasi dapat dilihat dari banyaknya sistem jaringan yang tersedia pada lokasi tersebut. Semakin tinggi tingkat aksesibilitas pada suatu lokasi maka akan semakin tinggi pula nilai sewa bangunan di lokasi tersebut. Masyarakat dapat melalui berbagai jalan untuk menjangkau koridor Jalan Raya Kalimalang, baik dari sisi bagian utara, selatan, dan barat Kota Administratif Jakarta Timur, maupun dari sisi bagian timur yang berbatasan dengan Kota Bekasi. Selain dapat dijangkau dari berbagai arah, koridor Jalan Raya Kalimalang juga dapat dilalui dengan berbagai moda transportasi (transportasi massal dan transportasi pribadi). Transportasi massal yang melalui koridor Jalan Raya Kalimalang terdiri dari mikrolet, metro mini, dan kopaja. Selain itu, 
rencananya koridor Jalan Raya Kalimalang juga akan dilalui oleh bus Transjakarta koridor 15 (Blok M-Kalimalang). Banyaknya pilihan moda transporasi menjadikan koridor Jalan Raya Kalimalang menjadi semakin mudah diakses oleh masyarakat (lihat gambar 3)

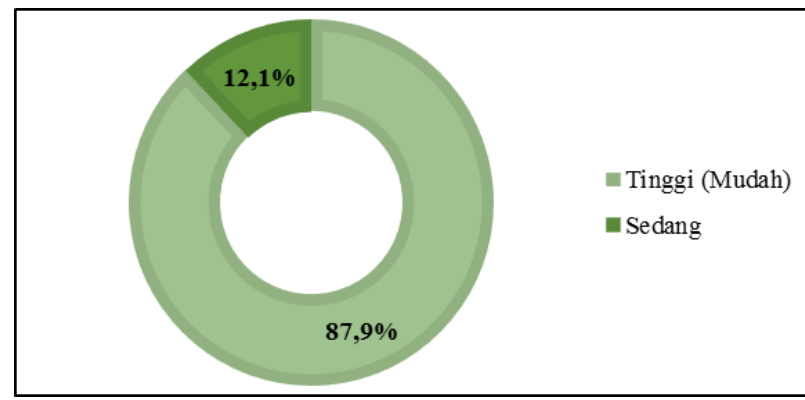

Gambar 3. Persentase Responden dalam Variabel Aksesibilitas Koridor Jalan Raya Kalimalang

(c) Infrastruktur. Dukungan transportasi menjadi suatu pertimbangan utama dalam pemilihan lokasi untuk aktivitas komersial. Kondisi dukungan transportasi di koridor Jalan Raya Kalimalang dikatakan sudah memadai. Terdapat berbagai macam moda transportasi untuk menjangkau koridor Jalan Raya Kalimalang. Jaringan jalan di koridor Jalan Raya Kalimalang saat ini dalam kondisi baik dan mampu menampung volume kendaraan setiap harinya, meskipun sering terjadi kepadatan pada jam-jam tertentu terutama pada pagi hari saat hari kerja.

Penyediaan air bersih di koridor Jalan Raya Kalimalang saat ini sudah melayani seluruh bangunan dengan sumur bor dan jaringan air perpipaan (PDAM). Jaringan air bersih PDAM yang melalui koridor Jalan Raya Kalimalang mendapat sumber air baku dari Sungai Kalimalang.

Koridor Jalan Raya Kalimalang telah terlayani oleh sistem jaringan listrik dari PLN. Kebutuhan daya listrik bangunan komersial berbeda-beda mulai dari 2200-53000 watt tergantung skala usahanya. Pasokan listrik oleh PLN di koridor Jalan Raya Kalimalang dikatakan telah memadai dan jarang terjadi pemadaman.

Jaringan persampahan sudah dikelola oleh pemerintah DKI Jakarta. Sampah di koridor Jalan Raya Kalimalang berasal dari aktivitas komersial. Sampah tersebut diangkut oleh petugas kebersihan menuju TPS Duren Sawit yang selanjutnya, diangkut menuju TPA Bantar Gebang, Bekasi oleh Dinas Kebersihan DKI Jakarta. Kondisi kebersihan di koridor Jalan Raya Kalimalang dapat dikatakan sudah terjaga dengan baik.

Koridor Jalan Raya Kalimalang dilalui oleh saluran tersier hingga saluran primer. Jaringan drainase tersier yang berada di sepanjang tepi koridor Jalan Raya Kalimalang sudah menggunakan saluran drainase tertutup. Sedangkan, jaringan drainase primer ialah Sungai Kalimalang yang saat ini dalam kondisi baik, tidak berbau, tidak dangkal, dan jarang ditemukan sampah yang tergenang. Setiap tahunnya, selalu dilakukan pengerukan dan pembersihan oleh petugas dari Dinas Tata Air Provinsi DKI Jakarta. Kondisi tersebut menjadikan koridor Jalan Raya Kalimalang jarang terjadi permasalahan bencana banjir.

Jaringan telekomunikasi di koridor Jalan Raya Kalimalang terdiri dari penggunaan telepon kabel, faximile, telepon seluler, serta internet (kabel dan fiber optic). Kondisi tersebut menjadikan masyarakat yang beraktivitas di koridor Jalan Raya Kalimalang dapat dengan mudah dalam berkomunikasi, baik melalui jaringan telepon, fax, maupun melalui jaringan internet. Dukungan transportasi, penyediaan jaringan air bersih, listrik, persampahan, drainase, serta telekomunikasi yang sudah baik dan memadai tersebut menjadi faktor pendorong yang mempengaruhi perkembangan aktivitas komersial di koridor Jalan Raya Kalimalang (lihat gambar 4).

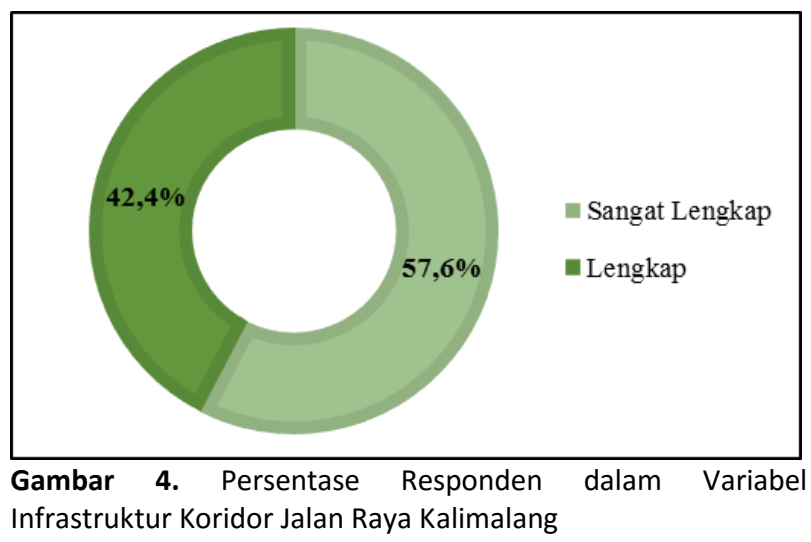

(d) Kesesuaian Kawasan. Kondisi topografi di koridor Jalan Raya Kalimalang termasuk dalam 
kelas kelerengan datar (0-2\%). Kondisi topografi yang datar menjadikan koridor Jalan Raya Kalimalang rawan bencana banjir. Namun, kondisi sistem jaringan drainase yang baik menjadikan koridor Jalan Raya Kalimalang dapat terhindar dari bencana banjir. Hal ini dapat dilihat dari koridor Jalan Raya Kalimalang yang memiliki jenis tanah yang mampu menampung bangunan berat serta kondisi lingkungan yang tidak rawan bencana banjir menjadikan koridor Jalan Raya Kalimalang cocok dikembangkan untuk aktivitas komersial. Dengan demikian, dapat disimpulkan bahwa tidak banyak ditemukan hambatan maupun pembatas fisik bagi pengembangan kegiatan komersial di koridor Jalan Raya Kalimalang. Dengan kata lain, aktivitas komersial di koridor Jalan Raya Kalimalang mampu bertahan dan berkembang di atas lahan tersebut.

\section{Harga Sewa Bangunan Komersial Koridor Jalan} Raya Kalimalang. Munculnya lahan sewa di koridor Jalan Raya Kalimalang terjadi sekitar tahun 2006, namun terdapat pula beberapa bangunan komersial yang sudah menyewa sejak tahun 1996an. Berdasarkan survei penelitian terhadap 66 responden, didapatkan bahwa harga sewa bangunan tertinggi sebesar Rp100.000.000/ tahun dan harga sewa bangunan terendah sebesar Rp20.000.000/ tahun. Harga sewa bangunan per $\mathrm{m}^{2}$ berkisar antara Rp500.000-Rp1.562.500 dengan rata-rata sebesar Rp924.030/ $\mathrm{m}^{2}$ (lihat gambar 5).

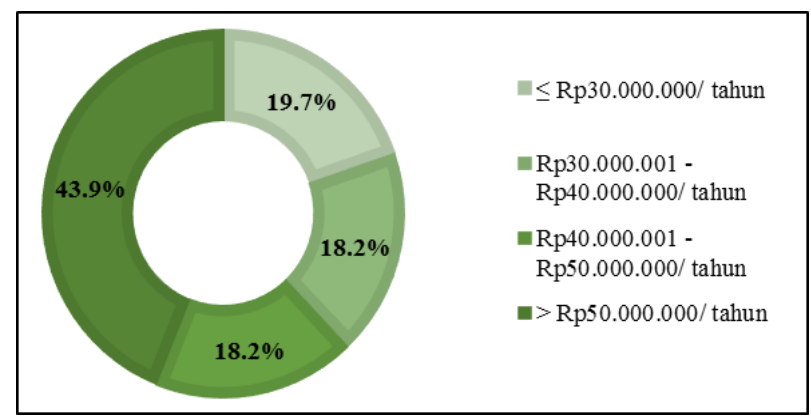

Gambar 5. Harga Sewa Bangunan Komersial di Koridor Jalan Raya Kalimalang

Bangunan komersial dengan harga sewa sebesar Rp30.000.001-Rp40.000.000/ tahun merupakan bangunan dengan rata-rata jenis usaha skala sedang (bengkel, kantor, salon, dan salon mobil). Sedangkan, harga sewa bangunan komersial > Rp50.000.000/ tahun merupakan bangunan komersial dengan rata-rata jenis usaha skala besar (bank, kantor, dan restoran). Adanya perbedaan harga sewa yang terjadi pada setiap bangunan komersial di koridor Jalan Raya Kalimalang dipengaruhi oleh beberapa faktor.

\section{Pengaruh Perkembangan Aktivitas Komersial} Terhadap Harga Sewa Bangunan Koridor Jalan Raya Kalimalang. Analisis pengaruh perkembangan aktivitas komersial terhadap harga sewa bangunan koridor Jalan Raya Kalimalang bertujuan untuk mengetahui ada tidaknya hubungan antara berkembangnya aktivitas komersial dengan harga sewa bangunan di koridor Jalan Raya Kalimalang. Berkembangnya aktivitas komersial di koridor Jalan Raya Kalimalang dapat dilihat dari semakin sedikitnya ketersediaan (supply) lahan untuk disewakan, semakin tingginya permintaan (demand) calon penyewa, serta semakin tingginya harga sewa bangunan (lihat gambar 6).

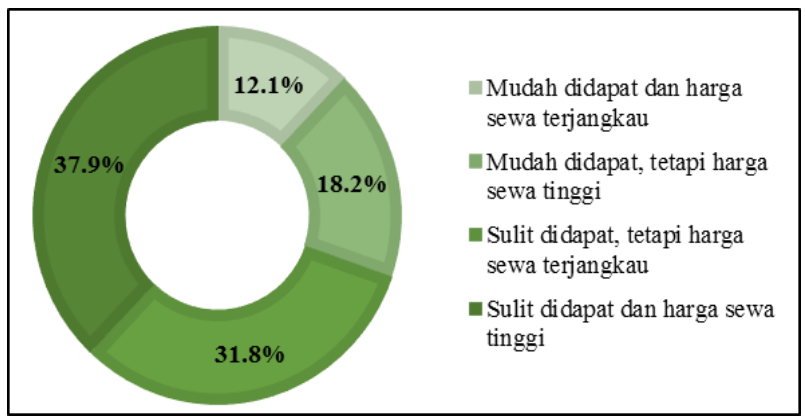

Gambar 6. Alasan Menyewa Bangunan Komersial di Koridor Jalan Raya Kalimalang

Sebanyak $69,7 \%$ responden dengan latar belakang penyewa baru (6 bulan-10 tahun) mengatakan bahwa mereka kesulitan dalam mendapatkan bangunan komersial di koridor Jalan Raya Kalimalang dikarenakan semakin sedikitnya bangunan yang masih kosong. Hal ini dibuktikan dengan hanya terdapat 9,04\% bangunan komersial yang belum laku disewa. Semakin sedikitnya ketersediaan dan semakin meningkatnya permintaan akan bangunan komersial di koridor Jalan Raya Kalimalang menunjukkan bahwa perkembangan aktivitas komersial di koridor Jalan Raya Kalimalang telah mempengaruhi harga sewa bangunan.

Faktor-Faktor yang Mempengaruhi Harga Sewa Bangunan Komersial Koridor Jalan Raya 
Kalimalang. Secara umum, harga sewa bangunan komersial di koridor Jalan Raya Kalimalang dipengaruhi oleh faktor-faktor yang sangat dominan, faktor-faktor tersebut memiliki daya tarik tersendiri bagi harga sewa bangunan komersial dan perkembangannya di koridor Jalan Raya Kalimalang. Dalam hal ini dibutuhkan analisis crosstab untuk mengetahui ada tidaknya hubungan antara harga sewa bangunan dengan variabelvariabel bebasnya. Harga sewa bangunan merupakan variabel terikat (dependent) yang akan dianalisis dengan 13 variabel yang akan digunakan menjadi variabel bebas (independent), yaitu ketersediaan bangunan, tata letak bangunan, aksesibilitas, infrastruktur, masalah lingkungan, lokasi, asal konsumen, kesesuaian koridor dengan kawasan komersial, bentuk bangunan, luas bangunan, usia bangunan, kondisi bangunan, serta jangka waktu sewa.

Tabel 1.

Hasil Analiss Crosstab

\begin{tabular}{|c|c|c|c|}
\hline $\begin{array}{c}\text { Hubungan } \\
\text { Harga Sewa } \\
\text { Bangunan } \\
\text { dengan } \\
\text { Variabel Lain }\end{array}$ & $\begin{array}{c}\text { Taraf } \\
\text { Signifikansi }\end{array}$ & $\begin{array}{c}\text { Nilai } \\
\text { Koefisien } \\
\text { Kontingensi }\end{array}$ & Keterangan \\
\hline $\begin{array}{l}\text { Ketersediaan } \\
\text { bangunan }\end{array}$ & 0,000 & 0,657 & $\begin{array}{c}\text { Berhubungan } \\
\text { erat }\end{array}$ \\
\hline $\begin{array}{l}\text { Tata letak } \\
\text { bangunan }\end{array}$ & 0,000 & 0,535 & $\begin{array}{c}\text { Berhubungan } \\
\text { erat }\end{array}$ \\
\hline Aksesibilitas & 0,457 & 0,195 & $\begin{array}{c}\text { Tidak } \\
\text { berhubungan }\end{array}$ \\
\hline Infrastruktur & 0,266 & 0,238 & $\begin{array}{c}\text { Tidak } \\
\text { berhubungan }\end{array}$ \\
\hline $\begin{array}{l}\text { Masalah } \\
\text { lingkungan }\end{array}$ & 0,055 & 0,397 & $\begin{array}{c}\text { Tidak } \\
\text { berhubungan }\end{array}$ \\
\hline Lokasi & 0,000 & 0,559 & $\begin{array}{c}\text { Berhubungan } \\
\text { erat }\end{array}$ \\
\hline Asal konsumen & 0,022 & 0,477 & $\begin{array}{c}\text { Berhubungan } \\
\text { cukup erat }\end{array}$ \\
\hline $\begin{array}{l}\text { Kesesuaian } \\
\text { koridor sebagai } \\
\text { kawasan } \\
\text { komersial }\end{array}$ & 0,022 & 0,357 & $\begin{array}{c}\text { Berhubungan } \\
\text { tidak erat }\end{array}$ \\
\hline $\begin{array}{l}\text { Bentuk } \\
\text { bangunan }\end{array}$ & 0,858 & 0,194 & $\begin{array}{c}\text { Tidak } \\
\text { berhubungan }\end{array}$ \\
\hline Luas bangunan & 0,000 & 0,571 & $\begin{array}{c}\text { Berhubungan } \\
\text { erat }\end{array}$ \\
\hline Usia bangunan & 0,015 & 0,371 & $\begin{array}{c}\text { Berhubungan } \\
\text { tidak erat }\end{array}$ \\
\hline $\begin{array}{l}\text { Kondisi } \\
\text { bangunan }\end{array}$ & 0,019 & 0,432 & $\begin{array}{c}\text { Berhubungan } \\
\text { cukup erat }\end{array}$ \\
\hline $\begin{array}{l}\text { Harga sewa } \\
\text { Jangka waktu } \\
\text { sewa }\end{array}$ & 0,008 & 0,503 & $\begin{array}{c}\text { Berhubungan } \\
\text { erat }\end{array}$ \\
\hline
\end{tabular}

Tabel 1 menunjukkan harga sewa bangunan komersial di koridor Jalan Raya Kalimalang dipengaruhi oleh sembilan variabel, yaitu ketersediaan bangunan, tata letak bangunan, lokasi, asal konsumen, kesesuaian koridor dengan kawasan komersial, luas bangunan, usia bangunan, kondisi bangunan, dan jangka waktu sewa. Hal ini ditunjukkan dari taraf signifikasi pada masingmasing faktor yakni $<0,05$ dimana $\mathrm{H}_{0}$ ditolak yang berarti ada hubungan antara harga sewa bangunan komersial dan faktor-faktor tersebut. Sedangkan, Nilai Koefisien Kontingensi menunjukkan erat lemahnya hubungan antar variabel. Variabel ketersediaan bangunan, tata letak bangunan, lokasi, luas bangunan, dan jangka waktu sewa memiliki koefisien kontingensi mendekati 1 yang berarti bahwa terdapat hubungan erat antara harga sewa bangunan dengan kelima variabel tersebut. Variabel asal konsumen dan kondisi bangunan memiliki hubungan yang cukup erat. Sedangkan variabel kesesuaian koridor dengan kawasan komersial dan usia bangunan memiliki hubungan yang lemah. Hal ini ditunjukkan dari nilai koefisien kontingensi yang mendekati 0 .

Selain sembilan tersebut, terdapat pula faktor lain yang ditemukan di lapangan yang bersifat intangible sehingga hanya pemilik bangunan dengan penyewa yang dapat merasakannya. Faktor lain tersebut diantaranya ialah tawarmenawar harga sewa bangunan antara pemilik bangunan dengan calon penyewa hingga terjadi kesepakatan harga sewa bangunan antar kedua belah pihak serta harga pasar yang berlaku pada antar bangunan komersial di koridor Jalan Raya Kalimalang.

\section{KESIMPULAN}

Pola aktivitas komersial di koridor Jalan Raya Kalimalang mengikuti jaringan jalan (ribbon) yang pertumbuhan aktivitasnya terkonsentrasi di sepanjang koridor. Harga sewa bangunan komersial di koridor Jalan Raya Kalimalang sangat beragam dan mengalami kenaikan dari waktu ke waktu seiring dengan perkembangan aktivitas komersial. Berdasarkan hasil survei lapangan, diperoleh bahwa harga sewa bangunan komersial yang berlaku di koridor Jalan Raya Kalimalang 
sebesar Rp20.000.000 - Rp100.000.000 per tahunnya.

Perkembangan aktivitas komersial di koridor Jalan Raya Kalimalang telah mempengaruhi ketersediaan bangunan komersial serta harga sewa bangunan dikarenakan permintaan yang terus meningkat, namun tidak diimbangi dengan penawaran yang ada. Berdasarkan hasil survei penelitian terhadap penyewa dengan jangka waktu menyewa antara 6 bulan-10 tahun, sebanyak $69,7 \%$ responden menyatakan bahwa bangunan komersial di koridor Jalan Raya Kalimalang sulit didapat, baik dengan harga sewa yang masih terjangkau maupun dengan harga sewa yang tinggi. Berdasarkan hasil analisis crosstab dapat disimpulkan bahwa terdapat sembilan faktor yang mempengaruhi harga sewa bangunan komersial di koridor Jalan Raya Kalimalang, yaitu ketersediaan bangunan, tata letak bangunan, lokasi, asal konsumen, kesesuaian koridor dengan kawasan komersial, luas bangunan, usia bangunan, kondisi bangunan, dan jangka waktu sewa.

Berdasarkan keseluruhan hasil analisis, maka dapat disimpulkan bahwa perkembangan aktivitas komersial menjadikan harga sewa bangunan di koridor Jalan Raya Kalimalang memilki harga yang cukup tinggi dengan ketersediaan bangunan komersial semakin sedikit. Keberagaman harga sewa pada setiap bangunan komersial di koridor Jalan Raya Kalimalang dipengaruhi oleh sembilan faktor dan faktor lain, yakni tawar-menawar harga sewa bangunan antara calon penyewa dengan pemilik properti dan harga pasar yang berlaku di koridor Jalan Kalimalang.

Berdasarkan kesimpulan tersebut, ada beberapa rekomendasi yang ditujukan bagi pemerintah, pemilik bangunan, serta rekomendasi untuk potensi penelitian selanjutya. Rekomendasi bagi pemerintah yaitu perlu adanya pengontrolan dalam mengendalikan harga sewa bangunan komersial agar harga sewa bangunan tetap dapat dijangkau oleh calon penyewa. Bagi pemilik bangunan komersial, perlu adanya penaksiran terhadap nilai dan harga bangunan bersama calon penyewa saat terjadi transaksi agar harga sewa masih terjangkau. Rekomendasi untuk studi lanjut, yaitu peranan regulasi terhadap penentuan harga sewa bangunan komersial dan pengaruh perkembangan aktivitas komersial di Koridor Jalan Raya Kalimalang terhadap keberlanjutan kawasan permukiman di wilayah sekitarnya.

\section{DAFTAR PUSTAKA}

Balchin, P. N., Kieve, J. L., \& Bull, G. H. (1988). Urban land economics and public policy: Springer.

Capello, R., \& Faggian, A. (2002). An economicecological model of urban growth and urban externalities: empirical evidence from Italy. Ecological Economics, 40(2), 181-198. doi: http://dx.doi.org/10.1016/S09218009(01)00252-X

Čeh, M., Viitanen, K., \& Peruš, I. (2012). A nonparametric CAE approach to office rents: Identification of Helsinki metropolitan area submarkets. Expert Systems with Applications, 39(1), 460-471. doi: http://dx.doi.org/10.1016/j.eswa.2011.07.037

Chong, T. T.-L., Shui, K. C.-W., \& Wong, V. H. (2014). The nexus between labor wages and property rents in the Greater China area. China Economic Review, 30, 180-191. doi: http://dx.doi.org/10.1016/j.chieco.2014.06.010

Clark, D., \& Pennington-Cross, A. (2016). Determinants of industrial property rents in the Chicago metropolitan area. Regional Science and Urban Economics, 56, 34-45. doi: http://dx.doi.org/10.1016/j.regsciurbeco.2015. 10.003

Dal Colle, A. (2016). The mechanics of commercial banking liberalization and growth. Journal of Banking \& Finance, http://dx.doi.org/10.1016/j.jbankfin.2016.04.0 14. doi: http://dx.doi.org/10.1016/j.jbankfin.2016.04.0 14

Du, J., Thill, J.-C., \& Peiser, R. B. (2016). Land pricing and its impact on land use efficiency in post-landreform China: A case study of Beijing. Cities, 50, 68-74.

doi: http://dx.doi.org/10.1016/j.cities.2015.08.014

Hartshorn, T. A. (1992). Interpreting the city: an urban geography: John Wiley \& Sons Incorporated.

Hu, S., Yang, S., Li, W., Zhang, C., \& Xu, F. (2016). Spatially non-stationary relationships between urban residential land price and impact factors in Wuhan city, China. Applied Geography, 68, 48-56.

doi: http://dx.doi.org/10.1016/j.apgeog.2016.01.00 6 
Kaiser, J. E. (2009). The Glass Industry in South Boston (doi:

https://books.google.co.id/books?id=604EykA A1YQC): University Press of New England.

Kheir, N., \& Portnov, B. A. (2016). Economic, demographic and environmental factors affecting urban land prices in the Arab sector in Israel. Land Use Policy, 50, 518-527. doi: http://dx.doi.org/10.1016/j.landusepol.2015.0 8.031

Kurniati, R., \& Erlambang, F. R. (2015). Changes the Pattern of Residential Space into Commercial Space in Chinatown Semarang. Procedia Environmental Sciences, 23, 307-314. doi: http://dx.doi.org/10.1016/j.proenv.2015.01.04 5

Sugiyono. (2013). Metode Penelitian Kuantitatif, Kualitatif, dan R\&D. Bandung: CV. Alfabeta.

Sungguh. (1992). Kamus Ekonomi Perdagangan. Jakarta: Media Pratama.

Tarigan, R. (2005). Perencanaan Pembangunan Wilayah. Jakarta: Bumi Aksara.
Wang, X., Biewald, A., Dietrich, J. P., Schmitz, C., LotzeCampen, H., Humpenöder, F., . . . Popp, A. (2016). Taking account of governance: Implications for land-use dynamics, food prices, and trade patterns. Ecological Economics, 122, 12-24. doi: http://dx.doi.org/10.1016/j.ecolecon.2015.11. 018

Wijaya, H. B. (1999). Improvement of Land Use Planning by Land Market Analysis Based on Land Bit-rent Model (Semarang Municipality as a Case Study). (MUM), University Rotterdam, Netherland.

Winarso, H., Hudalah, D., \& Firman, T. (2015). Periurban transformation in the Jakarta metropolitan area. Habitat International, 49, 221-229. doi: http://dx.doi.org/10.1016/j.habitatint.2015.05. 024

Yunus, H. S. (2005). Struktur Tata Ruang Kota. Yogyakarta: Pustaka Pelajar. 